\title{
Impacts of Wildfires on Hydrological Ecosystem Services ${ }^{+}$
}

\author{
João Pedro Nunes ${ }^{1, *}$, Cláudia Carvalho-Santos ${ }^{2}$ and Amandine Pastor ${ }^{3}$ \\ 1 CE3C-Centre for Ecology, Evolution and Environmental Changes, Faculdade de Ciências, Universidade \\ de Lisboa, 1749-016 Lisboa, Portugal \\ 2 CBMA-Centre of Molecular and Environmental Biology, University of Minho, 4710-057 Braga, Portugal; \\ c.carvalho.santos@bio.uminho.pt \\ 3 IRD - Institut de Recherche pour le Développement, France \& CE3C-Centre for Ecology, Evolution and \\ Environmental Changes, Faculdade de Ciências, Universidade de Lisboa, 1749-016 Lisboa, Portugal; \\ amandine.pastor22@gmail.com \\ * Correspondence: jpcnunes@fc.ul.pt \\ + Presented at TERRAenVISION 2019, Barcelona, Spain, 2-7 September 2019.
}

Published: 19 January 2020

\begin{abstract}
Forest and natural landscapes are usually considered to provide increased hydrological services over agriculture due to increased vegetation cover. Natural vegetation is expected to protect soils against erosion, regulate floods by increasing litter and soil water retention and decreased sediment yield. Afforestation is therefore used to control floods and prevent soil degradation, and water supplies are usually taken from forested watersheds. In the second half of the $X X^{\text {th }}$ century, agricultural abandonment in the northern rim of the Mediterranean led to extensive afforestation and renaturalization, and Mediterranean landscapes are now assumed to provide more hydrological services than before. However, Mediterranean forests are also prone to wildfires, which destroy the vegetation cover, changes soil properties with decreased soil water retention and create a highly mobile ash layer which can contaminate streams. These impacts temporarily negate the hydrological ecosystem services forests normally provided; and in regions subjected to frequent and recurring fires, it is possible that the long-term service provisioning is severely impacted. Nevertheless, forest management strategies ranging from emergency post-fire stabilization measures to structural landscape management can help mitigate these issues and prevent ecosystem service disruptions in fire-prone forests. This presentation will address this issue from a Mediterranean perspective, starting with an overview of post-fire impacts and consequences, and presenting results for a humid Mediterranean fire-prone area.
\end{abstract}

Keywords: forest hydrological ecosystem services; forest fire; burnt area hydrology

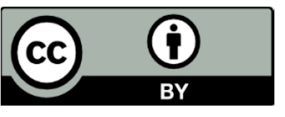

(C) 2020 by the authors. Licensee MDPI, Basel, Switzerland. This article is an open access article distributed under the terms and conditions of the Creative Commons Attribution (CC BY) license (http://creativecommons.org/licenses/by/4.0/). 